\title{
A Study of Discourse Strategies from the Perspective of Critical Analysis
}

\author{
Xinya Zuo \\ Shanxi Normal University, China
}

\begin{abstract}
Critical discourse analysis (CDA) is a form of reflective inspection of how discourses shape and influence us. It has been applied widely especially in political discourses which analyzes the potential characteristics of language and the social and cultural background generated in the text, committed to exposing the complex relationship between language, power and ideology with the aid of critical thinking. Generally, the theoretical framework of CDA is based on Halliday's systemic functional linguistics. Halliday believes that language has three metafunctions, namely ideational function, interpersonal function and textual function. These three achievements meet the needs of language users in three aspects including the description of the experience of objective world, the construction of social relations and the organization of discourse. As an important theory in systemic functional grammar, transitive system embodies the ideational function of language, which expresses people's real world experiences and the inner world in several processes. In addition, this kind of theory is based on the semantic configuration of Actor+Process. Therefore, this paper will make a critical discourse analysis of Donald Trump's inauguration speech in 2017 from the aspect of linguistic transitive system. The purpose of this paper is to analyze the language skills used by Mr.Trump and the discourse generating patterns of his presidential image, so that we can explore the ideology reflected behind the language and dig into the process of building the image of the president of the United States in Donald Trump's inauguration speech.
\end{abstract}

Index Term - critical discourse analysis, systemic functional grammar, transitive system, Donald Trump's inauguration speech

\section{INTRODUCTION}

In 1989, Fairclough, a leader in CDA, has pointed out in Language and Power that language is not merely a transparent intermediary, but a tool for expressing ideology and power. The relationship among language, power and ideology is implicit, so the main purpose of discourse analysis should be to make the relationship between language, power and ideology clear and to reveal the hidden determinants in the system of social relations and their implicit influence on the system. (Ji Weining, Xin Bin, 2009, p.21) CDA has been increasingly and widely applied in the analysis and study of various discourses, and has achieved fruitful results. It has greatly deepened people's understanding of the relationship between language and society. At the same time, the guiding theory of linguistics is mainly based on Halliday's systemic functional linguistics, which argues that language is social practice, the speaker is a social participant, the language system is regarded as a social symbol, and the use of language can be explained as a kind of social behavior. (Guo Zhiming, 2014, p.78) In other words, CDA can be regarded as a societal analysis from the linguistic perspective and a branch of critical theory in linguistics. It links the relevant historical and social context with appropriate linguistic methods, analyzes and reveals the power and dominion in the ideological field implied in the discourse, and studies the specific influence of discourse on reproduction and strengthening the power and dominion. (Chen Zhongzhu, 1995, p. 21).

As a representative and also popular target discourse, political speech discourse is definitely the focus area of CDA. The inauguration speech of US president Donald Trump on January 20, 2017, was an influential political speech text and with distinctive language characteristics. In speech discourse, speakers use various skills to achieve the purpose of their speeches. As a result, Mr. Trump is actually using the language skills to build a good image of him, and even to show audience the ideology behind it through language. Meanwhile, CDA, as an important way to expose the complex relationship among language, power and ideology, plays an extremely important role in the disclosure and presentation of this hidden purpose in political speech.

Therefore, from the perspective of meta-function of systemic functional linguistics, this paper will analyze and discuss the transitive system of Trump's inauguration speech, with a purpose to study the linguistic characteristics of the presidential image building in the speech. In addition, the paper can also provide readers with a research idea and method to interpret political speech discourse, so as to improve readers' sensitivity to comprehend political speech language. The sourse of the data of this study is from Guancha Syndicate (https://www. guancha.cn/ america/2017_01_21_390488_2.shtml).

\section{THEORETIC FOUNDATION}

A. The Connotation and Research Path of Critical Discourse Analysis (CDA) 
The term "critical discourse analysis" was put forward in language and Control in 1979 by Roger Fowler at first. (p.11) In 1995, Fairclough further explained about the relationship between language, power and ideology. (p.6) Ideology is the general concept and view held by human beings when they understand the world and sum up their experiences. It is a set of ideas, beliefs, especially political beliefs, that form the basis of the conduct of the masses, parties, and even the state. (Sinclair 1995:833) First of all, CDA introduces the critical tradition of social analysis into the study of language, and its critical theoretical origin is based on the critical tradition of western Marxism. CDA studies how the use of language embodies and constructs the perspectives, values and ways of talking of the powerful class, the purpose of which is to reveal the power and ideology behind it by studying the use of language, to highlight and criticize social injustice and so on. Therefore, CDA is an analysis tool with critical attitude, which is different from other types. (He Wei \& Wei Rong, 2018, p.64)

At home, Xin Bin (2000) has proposed that CDA aims to reveal the relationship between language, power and ideology from the perspective of linguistics, sociology and psychology through superficial language forms. This theoretical research mainly involves the influence of ideology on the process of discourse generation, the reaction of discourse to the form of consciousness, and how the two come from the social structure and the relationship between power and power, and how they serve it. (p.44)

In the study of CDA, the three analytical methods approved by most linguists are as follows: in 1981, M. Bakhtin put forward the intertextural analysis of discourse genre; in 1966, Fairclough raised discourse historical background analysis and Halliday put forward the systemic functional grammar in 1978. (Zhu Guisheng \&Huang Jianbin, 2016, p.59) These three analytical methods emphasis on different aspects. Systemic functional grammar is well-known as analyzing the functionality of the text and is consistent with the research purpose of this paper, therefore, we choose Halliday's systemic functional grammar as the theoretical basis.

\section{B. Systemic Functional Linguistics and Transitive System}

Huang Guowen (2017) discussed the relationship between systemic functional linguistics and ecological linguistics. It is pointed out that some theories of systemic functional linguistics can assist the linguistic analysis of the text studies in order to reveal the ideological meaning hidden behind it. It emphasizes the important linguistic view and methodological significance of systemic functional linguistics to critical discourse analysis and even ecological critical discourse analysis. (Mu Junfang, 2018, p.122)

Halliday once pointed out that the process of reflecting and constructing the objective world with linguistic symbols is also the process of understanding the present world. (He Wei \& Wei Rong, 2017, p.599) According to Halliday, language can roughly achieve three meanings in different contexts: ideational meaning, interpersonal meaning and textual meaning. They correspond to three meta-functions of language respectively, namely ideational function, that is, all kinds of empirical fragments and their logical relations recognized by human beings; interpersonal function refers to the function of speech and the attitude of the speaker, judgment, etc.; textual function means that language forms words and sentences into coherent texts by its own mechanism in order to express ideational and interpersonal meaning. (Yang Xueyan, 2012, p.32)

The transitivity is a semantic system that expresses the idational function and a network which involves six types of process (namely material process, mental process, relational process, vernal process, behavioral process, existential process) as well as the participants and environmental elements. In general, this paper is an attempt of critical discourse analysis, which is based on the systemic functional grammar and follows the assumption that "Form is the realization of meaning".

\section{Corpus Selection}

The text of political speech is different from face-to-face communication and has the characteristics of one-sideness. The speaker takes on the role of information sender and fully demonstrates his attitude and observation perspective on the event. These characteristics make the political speech text more inclined in the choice of position, and the choice of language is more valuable, so it is the main research object of CDA. (Kang Junying \& Li Fengqin, 2018, p.25)

Through inauguration speech, the public were given the idea of future policies and livelihood measures of the country by president. Therefore, the speakers and his team organize the logic and words carefully, integrate the political thought into the writing arrangement, and achieve the predetermined political purpose and effect through various linguistic means. (Li Hui, 2018, p.63) Hence, based on American president Donald Trump's inauguration speech, this paper explores the language skills of his speech from the perspective of CDA, choosing transitive system to excavate the implicit meaning behind his discourse and the relationship between power and ideology and the process of building the image of the president.

\section{CRitical Discourse Analysis Based on Transitive System}

Ideational meaning is the product of the interaction of human cognitive system and language system. Human recognize the phenomena in the real world through the brain, categorize and conceptualize the pieces of experience in the brain through the language system. (Yang Xueyan, 2012, p. 33) Halliday believes that people can interpret their experiences in the real world as an operable group of processes through transitive systems. transitive involves the 
"content" of the whole clause, that is, covering the process, the participants in the process and the related environmental components. (He Wei \& Wei Rong, 2016, p.1) That is to say, the transitive model is based on the configuration of "actor+process". The basic distinction between six processes (namely, the material process, the mental process, and verbal process, relational process, behavioral process, and existential process) is between experience outside of us and that inside us. They are the summary and classification of the means of expressing of the ideational function of clauses. According to statistics, there are 131 clauses in Trump's speech text. The following will carry on the discourse analysis from six kinds of action processes.

\section{A. Material Process}

The material process is used to represent the process of doing something such as watching and drinking (Hu Zhuanglin, 2013, p.281), and is used to identify the material world experience of human beings. (Wang Zhenhua, 2018, p.60) This kind of process is generally represented by dynamic verbs, movers and the objectives of actions. For instance, in the clause "The letter was written by Tom", systemic functional linguists describe "Tom" as the actor (also called the agent), that is, the subject responsible for the action process "write", and "The letter" as the goal (the affected), meaning the objective which is acted upon.

The president's inauguration speech is of great significance, and its main purpose is to arouse the enthusiasm and support of the people by publicizing the policy agenda of the new government. Of the 131 clauses in this discourse, the material process appeared 83 times, accounting for the vast majority of clauses. The arrangement and choice of language in the material process reflect the purpose and ideology that the speaker wants to convey. Trump mainly uses the material process in two kinds of narration: one is the narration of the existing problems and contradictions in the United States, the other is the narration of how to solve the problem immediately after Trump takes office. We will choose a few examples for discourse analysis and excavate the deep meaning behind the word.

A. "For too long,a small group in our nation's Capital has reaped the rewards of govemment while the people have borne the cost." (4"34')

B. "The wealth of our middle class has been ripped from their homes and then redistributed across the entire world." $(10$ '15')

C. "We will bring back our jobs. We will bring back our borders. We will bring back our wealth. And we will bring back our dreams." ( 12 '15')

First of all, sentence A is consisted of two clauses. The participants in the first clause are "a small group in our nation's capital" (agent) and "the reward of government" (affected), while in the second clause are "the people"(agent) and "the cost" (affected). By using the conjunction "while", a strong contrast between the former and the latter participant's role system is built, reflecting the corruption of the former government which greatly hurts the interests of the American people. It expresses Trump's emphasis on the issue of people's livelihood and the interests of the American people.

The sentence B, on the other hand, further focuses the situation of the American middle class. The semantic configuration of this clause is "action process (ripped and redistributed) + affected (the wealth of our middle class)". We need to pay attention to the choice of predicate verbs here. The word "rip" literally refers to tear or pull quickly or forcibly away from sth. or sb, and is used here to indicate how deeply the middle class people are hurt. The usage for this sentence can be understood from two aspects: First, Trump was born in a middle-class American family. The growing environment enables him to have an extraordinary empathy for the middle-class and thus has deeper sense of the living condition for them. Second, the theme of Trump's campaign is to help the middle bourgeoisie. He has made many promises to them to safeguard their interests.

Finally, the third one comprises four clauses which all begin with sentence pattern "We will bring back". This expresses the determination of Mr. Trump to rebuild the United States, returning benefits to the people and has a certain pragmatic presupposition, that is, the US minority interests and improper national policies have caused the American people to lose their job opportunities, tranquility, wealth and dreams. The repeated use of "We will bring back" indicates that they emphasize the interests of the American people and the determination to take back the interests for the American people, and also shape the image of a president who strives for the interests of the American people. (Li Hui, 2018, P.64)

\section{B. Mental Process}

The Mental Process indicates the process of "perception", "reaction" a, "cognition" and other mental phenomena(Hu Zhuanglin,2013, p.281), used to understand the experience of people's consciousness, involving two participants: the sensor and the phenomenon. (Wang Zhenhua, 2018, p.60) Verbs such as wish, think, love, fall in this group. For instance, the subject "I" in the clause "I hate this terrible weather" is regarded as the sensor, and the thing "this terrible weather"sensed as the phenomenon. There are totally 14 mental processes in this speech.

As for sentence D, the goal and phenomenon achieved by the predicative verb "share" is a series of parallel phrases. This sentence makes the speaker close the distance between himself and the audience, integrates the individual identity into the social group identity, emphasizes the same American citizenship as the people, and aims to arouse the emotional resonance of the people. Furthermore, the sentence $\mathrm{E}$ is occurred nearly at the end of the speech and manifests his determination and great ambition to rejuvenate the United States with all the American people. Meanwhile, 
the subjective chosen in this clause is still "we" ,sending a message that the future and direction of the United States is determined by all Americans once again. Everyone should be involved in the effort and new initiatives of revitalizing the US economy.

D. "We share one heart, one home, and one glorious destiny." (8"48')

E. "Finally, we must think big and dream even bigger." (15"27')

\section{Relational Process}

This kind of process often connects two participants together and is generally consisted of attributive relational process and identifying relational process, (Hu Zhuanglin,2013, p.281) whose participants is carrier and attribute, token and value, respectively. (Wang Zhenhua, 2018, p.60) In the clause "The princess is graceful", "the princess" is the carrier while "graceful" the attribute. From another aspect, if the sentence "Charlotte is the captain" is used to answer "who is Charlotte", then "Charlotte" is the token and "the captain" is the value.

The relational process has occurred 21 times in this speech discourse, relatively more than other process types. It focuses on description of the relationship between scenarios, attributes, and features among people. Through this process the audience recognizes their affiliation with the country and the new government, and thus enhances a sense of belonging to the state. As for discourse F, on the one hand, quantified language can strengthen the momentum of Trump's speech and provoke the enthusiasm of the audience and convince them. On the other hand, this sentence emphasizes "your time" and "your celebration", which is intended to indicate the determination of building a democratic and nation. The sentence G composes of two clause, and the semantic configuration of which is "their dreams(token) + are + our dreams (value)" and "their success(token) + will be + our success(value)". According to context, pronoun "their" used in G refers to the American citizens who straitened in their circumstances. Therefore, this sentence shows his attitude of caring for the suffering of the people, taking the people's livelihood issue as a priority and hoping to arouse all the people to resist the determination to plunder and the enthusiasm for rebuilding the new order.

F. "This is your day. This is your celebration." (5"56')

G. "Their dreams are our dreams; and their success will be our success." (8"37')

\section{Behavioral Process}

The behavioral process covers mental or material processes such as coughing, crying, breathing, gazing, etc. There is only one participant- behavior, the subject of the action, and generally a person. ((Hu Zhuanglin,2013, p.281) Thus, there are still differences between behavioral process and those two processes in that the action achieved by behavioral process is not performed on anything. For example, "The students laughing the teacher." is meaningless, whereas "The students respect the teacher." is meaningful.

There are totally 8 behavioral processes achieved in this inauguration speech discourse. In the previous campaign speech, Trump's campaign slogan“Keep America great” has become familiar to Americans. (Li Hui, 2018, p.65) The behavioral verbs (not fail, thrive and prosper) chosen here are still highlighting Trump's strong confidence in leading the United States on a path of greater prosperity. And discourse $\mathrm{H}$ also encourages the people to unite, to be bold in innovation, exploring and overcoming difficulties.

H. "We will not fail. Our country will thrive and prosper again." (16"22')

\section{E. Verbal Process}

Verbal process is used mainly in exchanging information. The predictive verbs belong to this category usually include speaking, asking, explaining and so on. ((Hu Zhuanglin, 2013, p.281) The participants involved in this type are sayer, verbiage, receiver and target. (Wang Zhenhua, 2018, p.61) We can understand it though following example: the semantic configuration of the clause "Can you explain the requirement to students?" is "sayer(you)+verbal process(explain)+verbiage( the requirement)+receiver(students)".

There is merely one verbal process throughout the entire discourse, that is the clause I. Trump portrays the brilliant vision of the unity of the American people in the future by using the spirit of nationalism to encourage the people to unite, and to create. In a context with strong religious air, Trump combines his beliefs with the spiritual pillars of thousands of people, using the Bible as a medium to evoke resonance among the people, which is following most consistent way of the presidential inauguration speeches in American history.

I. "The Bible tells us, "how good and pleasant it is when God's people live together in unity." (14"29')

\section{F. Existential Process}

The existential process indicates the existence or occurrence of something. Each existential process has only one participant, that is, existent. (Hu Zhuanglin, 2013, p.282) It consists of clauses in which there acts as grammatical subject, for instance "There was no coffee" and "There seemed to be a contradiction", and so on. There are totally 4 existential processes in this speech discourse.

The clause $\mathbf{J}$ guides the follow-up text to criticize previous US presidents and governments, denouncing the immoral upper American interest groups and inappropriate national policies that have led the American people to lose their jobs, tranquility, wealth, and dreams they are supposed to enjoy, and to give examples of the tragic experiences of the 
American people. However, the relatively optimistic economic situation can not eliminate the fear of the people. They concern about future life and the country's economic position and globalization, and also care for immigration and terrorism. By using the clause "There should be no fear", Trump encourages the people: the new country, the bright vision and the prosperous economy will return to the people as he takes office. In a word, the existential process always plays a role in emphasizing the argument and leading to the following topic.

J. "There was little to celebrate for struggling families all across our land." (5"19')

K. "There should be no fear - we are protected, and we will always be protected." (15"00')

\section{CONCLUSION}

Through the analysis of Mr Trump's inauguration speech from the perspective of transitive system, this paper verifies the operability and practicability of critical discourse analysis of systemic functional grammar in speech discourse. The article finds that Trump's inauguration speech uses a multilingual strategy to build his presidential image and inspire the audience: Using abundance of material processes to demonstrate his commitment to the people and his vision for the future of the United States, aiming to build a presidential image of being responsible, doing practical measures, and serving the people. The 14 mental processes play the role of expressing the emotional atmosphere and driving the audience's emotions and manifest his determination and great ambition to rejuvenate the United States with all the American people. On the other hand, the use of a large number of relational processes also enhances the empathy of the audience and as a result to inspire the audience's sense of mission and to encourage the audience to actively participate in the development of the United States.

In summary, this paper analyzes the language skills and text generation mode of Trump's inauguration speech, and explores the ideology behind it. At the same time, it provides a research idea and method for readers to interpret political discourse to improve language sensitivity and to enhance the ability for readers to preferably understand and interpret the discourse.

\section{REFERENCES}

[1] Bin Xin. (2000). Critical Linguistics and Critical Analysis of English News Discourse. Foreign Language Education, (04):44-48.

[2] Fairclough. (1995). Critical Discourse Analysis: The Critical Study of Language. London: Longman.

[3] Fowler. (1979). Language and Control. London: Routledge.

[4] Guisheng Zhu \& Jianbin Huang. (2016). China's “One Belt, One Road” Strategy in the Vision of American Mainstream Media. Press Circles, (17):58-64.

[5] Guowen Huang. (2017). From Systemic Functional Linguistics to Ecolinguistics. Foreign Language Education, (5): 1-7.

[6] Hu Zhuanglin. (2013). Linguistics: A Course Book. Beijing: Peking University Press.

[7] Hui Li. (2018). A Study on Trump's Inaugural Address from the Perspective of Identity Construction. Journal of Hebei North University (Social Sciences Edition), 34(06): 63-65+71.

[8] Junfang Mu. (2017). A Review of the Research on Domestic Critical Discourse Analysis in 2017. Journal of Tianjin Foreign Studies University, 25(06):120-133.

[9] Junying Kang \& Fengqin Li. (2018). A Critical Analysis of Reporting Verbs in Political News Discourse. Foreign Languages Research, 35(03): 25-30.

[10] Sinclair, J. (1995). Collins Cobuild English Dictionary. London: Harper Collins Publishers Limited.

[11] Weining Ji \& Bin Xin. (2009). The Examination On the Thoughts of Critical Discourse Analysis by Fairclough. Foreign Language and Literature, 25(06): 21-25.

[12] Wei He \& Rong Wei. (2017). An analytical framework of transitive for international ecological discourse. Modern Foreign Languages (Bimonthly), 40(05): 597-607+729.

[13] Wei He \& Rong Wei. (2018). The Paradigm of Discourse Analyses and the Theoretical Foundation of Ecological Discourse Analysis. Dangdai Xiucixue, (05): 63-73.

[14] Xiao Wang. (2017). The full text of Trump's inaugural address, from https://www. guancha.cn/america/2017_01_21_390488_2.shtml.

[15] Xueyan Yang. (2012). Discourse Analysis from the Perspective of Systemic Functional Linguistics. Foreign Language Education, 33(02): 31-36.

[16] Zhongzhu Chen. (1995). Critical linguistics review. Foreign Language Teaching and Research, (01): 21-27.

[17] Zhenhua Wang. (2018). Translating Chinese Clause Processes and Participants into English: A Perspective from transitive System. Foreign Languages Research, 35(04): 59-65+112.

[18] Zhiming Guo. (2014). Positive Discourse Analysis with Appraisal Theory. Journal of North University of China (Social Science Edition), 30(02): 78-81.

Xinya Zuo was born in Linyi, Shanxi, China in 1995. She is a graduate student and currently studying in Shanxi Normal University. Her research interests include linguistics, critical discourse analysis and ecological discourse analysis. 